\title{
Significant Cutaneous Improvement within Two Months of Surgery
}

\author{
Waseem Aziz ${ }^{a, b}$ Mohammed Al felasic ${ }^{c}$ Piere Najm ${ }^{d}$ Khaled M. Aldahmani ${ }^{e}{ }^{f}$ \\ aDepartment of Neurosurgery, Mediclinic, Al Ain, UAE; ' ${ }^{\circ}$ Department of Neurosurgery, Alexandria University,

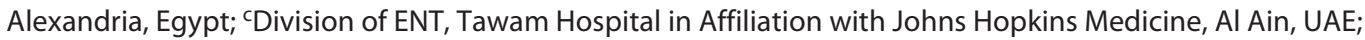 \\ IImperial College London Diabetes Center, Abu Dhabi, UAE; e Division of Endocrinology, Tawam Hospital in \\ Affiliation with Johns Hopkins Medicine, AI Ain, UAE; ' Department of Medicine, Department of Medicine, United \\ Arab Emirates University, Al Ain, UAE
}

A 38-year-old male had 4 years history of type 2 diabetes mellitus with no micro- or macrovascular complications. He was on 1,000 $\mathrm{mg}$ of Metformin twice daily. He had excessive sweating and progressive facial changes. Physical examination was notable for enlarged extremities with thick skin, deep nasolabial folds, and coarse facial features (Fig. 1a). His labs showed A1c of $7.2 \%$, random growth hormone $(\mathrm{GH}) 11.9 \mathrm{mcg} / \mathrm{L}$ and insulin-like growth factor-1 (IGF-1) level $128.2 \mathrm{nmol} / \mathrm{L}$ (NR: 12.4-28.3). Pituitary MRI revealed a $1-\mathrm{cm}$ adenoma. Within 2 months of surgery, he noted significant improvement in his facial appearance (Fig. 1b). Also, his glycemic control had improved and he was able to stop metformin within 6 months of surgery. Labs showed normal IGF-1 and GH, and his A1c dropped to $6.1 \%$. Repeat pituitary MRI showed complete resection of the pituitary adenoma. At his last visit (4 years after surgery), his IGF-1 remained within normal range, and his $\mathrm{HbAlc}$ was $6.2 \%$ on diet control alone.

What is your diagnosis?
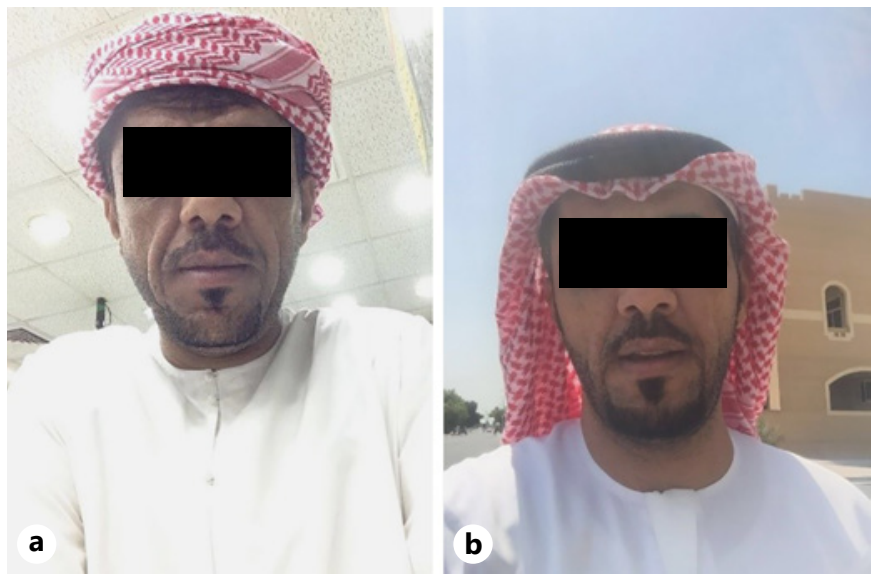

Fig. 1. Facial changes before (a) and after (b) successful adenoma resection.

\section{karger@karger.com www.karger.com/dde \\ Karger $\stackrel{\text { ' }}{=}$}

BOPEN ACCESS
(C) 2020 The Author(s)

Published by S. Karger AG, Basel

This article is licensed under the Creative Commons AttributionNonCommercial-NoDerivatives 4.0 International License (CC BY NC-ND) (http://www.karger.com/Services/OpenAccessLicense) Usage and distribution for commercial purposes as well as any distribution of modified material requires written permission.
Khaled M. Aldahmani

Medicine Department, Tawam Hospital

Al Ain, 15258 (UAE)

kmdahmani@seha.ae 
Acromegaly is a rare disease with increased morbidity and mortality [1]. Chronic exposure to high levels of GH and IGF-1 leads to profound changes in many body systems, including the musculoskeletal and integumentary system [2]. Common skin features in acromegaly include facial wrinkles, deep nasolabial folds, thickening of skin, sweating, and large nose and lips [3]. Achieving disease control is associated with improvement of cutaneous, metabolic, respiratory, and cardiovascular manifestations of acromegaly in addition to reduction in mortality [4]. However, the time to which these changes occur, especially the cutaneous findings, is not well established. Our patient had a significant and prompt improvement of his facial features (Fig. 1b) within 2 months of surgery. Similarly, he achieved a remarkable glycemic control off metformin. This case highlights the amelioration of the cutaneous and metabolic complications of acromegaly shortly after achieving disease control.

\section{Statement of Ethics}

The patient gave a written informed consent to publish their case, including the images.

\section{Conflict of Interest Statement}

The authors have no conflicts of interest to declare.

\section{Funding Sources}

There is no funding for this publication.

Keywords

Pituitary adeoma $\cdot$ Acromegaly $\cdot$ Surgery $\cdot$ Skin

manifestations

\section{References}

Cutaneous Improvement after Disease Control
1 Capatina C, Wass JA. 60 years of neuroendocrinology: acromegaly. J Endocrinol. 2015; 226(2):T141-60.

2 Abreu A, Tovar AP, Castellanos R, Valenzuela A, Giraldo CM, Pinedo AC, et al. Challenges in the diagnosis and management of acromegaly: a focus on comorbidities. Pituitary. 2016;19(4):448-57.
3 Akoglu G, Metin A, Emre S, Ersoy R, Cakir B. Cutaneous findings in patients with acromegaly. Acta Dermatovenerol Croat. 2013;21(4): 224-9.

4 Ben-Shlomo A, Sheppard MC, Stephens JM, Pulgar S, Melmed S. Clinical, quality of life, and economic value of acromegaly disease control. Pituitary. 2011;14(3):284-94. 